\title{
Immediate ozone effects on heart rate and repolarisation parameters in potentially susceptible individuals
}

\author{
Regina Hampel, ${ }^{1}$ Susanne Breitner, ${ }^{1,2}$ Wojciech Zareba, ${ }^{3}$ Ute Kraus, ${ }^{1,2}$ Mike Pitz, ${ }^{1,4}$ \\ Uta Geruschkat, ${ }^{1}$ Petra Belcredi, ${ }^{1,5}$ Annette Peters, ${ }^{1}$ Alexandra Schneider, ${ }^{1}$ for the \\ Cooperative Health Research in the Region of Augsburg (KORA) Study Group
}

\begin{abstract}
- Additional materials are published online only. To view these files please visit the journal online (http://oem.bmj. com/content/69/6.toc).

${ }^{1}$ Helmholtz Zentrum München, German Research Center for Environmental Health, Institute of Epidemiology II, Neuherberg, Germany

${ }^{2}$ Institute of Biometrics and Epidemiology, Ludwig Maximilians University of Munich, Munich, Germany ${ }^{3}$ Cardiology Division, University of Rochester Medical Center, Rochester, New York, USA ${ }^{4}$ ESC-Environmental Science Center, University of Augsburg, Augsburg, Germany ${ }^{5}$ Hospital of Augsburg, MONICA/KORA Myocardial Infarction Registry, Augsburg, Germany
\end{abstract}

\section{Correspondence to} Regina Hampel, Helmholtz Zentrum München-German Research Center for Environmental Health, Institute of Epidemiology II, Ingolstädter Landstr. 1, 85764 Neuherberg Germany; regina.hampel@ helmholtz-muenchen.de

Accepted 8 August 2011 Published Online First 17 November 2011

\begin{abstract}
Objectives Elevated ozone levels have been associated with cardiovascular morbidity and mortality. We investigated the effects of ozone on heart rate $(H R)$ and repolarisation parameters in potentially susceptible populations.
\end{abstract}

Methods Between March 2007 and December 2008, 363 ECG recordings including $>20001 \mathrm{~h}$ intervals were measured in 64 individuals with type 2 diabetes or impaired glucose tolerance and in 46 healthy individuals with a potential genetic predisposition on the detoxification pathways from Augsburg, Germany. Associations between $1 \mathrm{~h}$ averages of ozone and HR, Bazett-corrected OT-interval (OTc), T-wave amplitude and T-wave complexity were analysed using additive mixed models. A variable indicating season and participants' location during the $1 \mathrm{~h}$ ECG recordings (summer and outdoors vs winter or indoors) was used as a potential ozone effect modifier.

Results We observed concurrent and 1-4 h lagged increases in HR of $0.5-0.7 \%$ for each $20 \mu \mathrm{g} / \mathrm{m}^{3}$ increase in ozone. These effects were stronger (1.0-1.2\%) when participants were outdoors during the summer. We detected in all participants a concurrent $(-1.31 \%$; $95 \%$ $\mathrm{Cl}-2.19 \%$ to $-0.42 \%)$ and $1 \mathrm{~h}$ lagged $(-1.32 \%$; $-2.19 \%$ to $-0.45 \%)$ T-wave flattening. Elevated ozone levels were associated with $1 \mathrm{~h}(2.12 \% ; 0.81$ to 3.52$)$ and $2 \mathrm{~h}$ lagged (1.89\%; $0.55 \%$ to $3.26 \%$ ) increases in T-wave complexity. However, no effects were seen for OTc. Ozone effects were generally more pronounced in individuals with metabolic disorders than a potential genetic predisposition.

Conclusions Changes in repolarisation might contribute to underlying pathophysiological changes associated with the link between elevated ozone levels and reported adverse cardiovascular outcomes.

\section{INTRODUCTION}

Many epidemiological studies have reported ozonerelated increases in both respiratory and cardiovascular morbidity ${ }^{1-3}$ and mortality. ${ }^{4-6}$ Precursors of these events might be local and systemic inflammatory responses and alterations in cardiac rhythm. Accordingly, Chuang et al have shown both increases in inflammatory blood markers and decreases in heart rate variability (HRV) in association with elevated levels of 1-3-day averages of ozone in young and healthy adults. A study

\section{What this paper adds}

- Elevated ozone levels have been associated with cardiovascular morbidity and mortality.

- There is limited knowledge about the effects of ozone on electrocardiogram (ECG) parameters.

- We investigated on an hourly basis the effects of ozone on heart rate and repolarisation parameters in 64 individuals with metabolic disorders and in 46 healthy individuals with a potential genetic predisposition.

- We observed immediate ozone effects on heart rate and repolarisation which were stronger in individuals with metabolic disorders.

- Interventions to further reduce ozone pollution would benefit public health, even in regions with relatively low ozone levels.

conducted in elderly participants with coronary artery disease detected a decrease in the root mean square of successive differences (RMSSD) due to increases in 30 min up to 5-day averages of ozone. ${ }^{8}$ However, knowledge about the effects of ozone on markers of HRV is still very limited. A potential influence of ozone on cardiac repolarisation has received even less attention. A few studies have investigated the influence of particulate matter (PM) or gaseous air pollutants on repolarisation. The authors reported changes in the QT-interval, $\mathrm{T}$-wave alternans, $\mathrm{T}$-wave amplitude and $\mathrm{T}$-wave complexity in association with elevated air pollution levels. ${ }^{9-14}$ It is hypothesised that a prolonged QT-interval and T-wave abnormalities might trigger the onset of arrhythmias ${ }^{15}$ and increase the risk for coronary death. ${ }^{16}$ Whether changes in repolarisation are an intermediate step between the reported ozone effects and adverse cardiac events needs to be investigated.

It has been shown that the elderly, women and individuals with diabetes are particularly susceptible to ozone exposure. ${ }^{2}{ }^{17}$ As the prevalence of diabetes is increasing worldwide, it is important to explore potential ozone effects especially in this subpopulation. Ozone may act on the autonomic function via oxidative stress pathways. ${ }^{18}$ Hence, individuals with a deletion in the glutathione S-transferase M1 (GSTM1) gene indicating reduced 
protection against oxidative stress ${ }^{19}$ might also be susceptible to the effects of ozone.

Ozone is not directly emitted but is formed through complex reactions in the atmosphere. Therefore, ozone effects on health outcomes might be confounded by other secondary (eg, sulphate) or combustion-related pollutants (eg, ultrafine particles and particulate matter) produced concurrently with ozone. ${ }^{20}$

The main objective of our study was to investigate the acute effects on an hourly basis of ozone on heart rate (HR) and repolarisation parameters in healthy subjects with a potential genetic predisposition and in individuals with type 2 diabetes (T2D) or with impaired glucose tolerance (IGT) indicating an enhanced risk for diabetes. Furthermore, we implemented two-pollutant models to check whether ozone effects are confounded by other air pollutants. To our knowledge only one chamber study ${ }^{21}$ has explored the combined and separate effects of concentrated ambient particles and ozone on ventricular repolarisation.

\section{METHODS}

\section{Study design and study population}

As part of the University of Rochester Particulate Matter Center investigations, a prospective panel study was conducted between 19 March 2007 and 17 December 2008 in Augsburg, Germany. Individuals with T2D or IGT and healthy individuals with a potential genetic predisposition on the detoxification pathway were recruited from the KORA (Cooperative Health Research in the Region of Augsburg) follow up which was conducted in 2006-2008. TD2 was either physician-diagnosed or indicated by medication use. All other participants had an oral glucose tolerance test (OGTT). Participants with a fasting glucose level $>125 \mathrm{mg} / \mathrm{dl}$ or a $2 \mathrm{~h}$ OGTT glucose level $\geq 200 \mathrm{mg} /$ $\mathrm{dl}$ were also defined as having TD2. IGT was defined as $2 \mathrm{~h}$ OGTT glucose levels $\geq 140 \mathrm{mg} / \mathrm{dl}$ but $<200 \mathrm{mg} / \mathrm{dl}$. The potential genetic predisposition was defined as having the null polymorphism for GSTM1 and either two minor alleles of the single nucleotide polymorphism rs1205 located in the C-reactive protein gene or at least one minor allele of the single nucleotide polymorphism rs 1800790 located in the fibrinogen gene $F G B$. In our study, all individuals participated in up to four repeated ECG recordings scheduled every 4-6 weeks on the same weekday and at the same time of the day. Data on health status, medication use, disease and smoking history were gathered at a baseline visit. Current smokers and individuals with an intake of platelet aggregation inhibitors except for acetylsalicylic acid, a myocardial infarction (MI) and/or interventional procedure (PTCA, bypass surgery) $<6$ months before the start of the study, chronic inflammatory diseases such as Crohn's disease, ulcerative colitis or rheumatoid arthritis, an implanted pacemaker, atrial fibrillation, allergy to latex and thrombosis or shunt in an arm were excluded. All participants gave written informed consent and the study protocol was approved by the Ethics Commission of the Bavarian Chamber of Physicians ('Bayerische Landesaerztekammer').

\section{Clinical measurements}

Participants were equipped with a 12-lead Mortara H12 digital Holter recorder (Mortara Instrument, Milwaukee, Wisconsin, USA). They then left the study centre to pursue their daily routines and returned after $4-6 \mathrm{~h}$. ECG parameters such as HR and repolarisation parameters were determined on an hourly basis. Therefore, repeated ECG recordings for each participant and repeated $1 \mathrm{~h}$ averages of ECG parameters within one recording were available. Only individuals with at least one ECG recording with at least a $2 \mathrm{~h}$ duration were used for analysis. ECG parameters of interest were HR, Bazett-corrected OTinterval (OTc), T-wave amplitude (Tamp) and T-wave complexity (Tcomp). ${ }^{11}$ Tcomp represents the shape of the vectocardiographic $\mathrm{T}$-wave loop which reflects the spread of repolarisation throughout the myocardium. Tcomp is the ratio of the short to long axis of the loop and is expressed as a percentage. A normal T-wave loop is long and narrow which projects to the ECG as a tall and distinct T-wave. An abnormal T-wave loop is wider, usually represented by lower and flatter $\mathrm{T}$-waves, and has greater complexity.

\section{Ozone, air pollution and meteorological data}

Hourly means of ozone levels were available from a monitoring site belonging to the Bavarian Environment Agency. Hourly means of air temperature, relative humidity, barometric pressure, particulate matter with an aerodynamic diameter below $2.5 \mu \mathrm{m}$ $\left(\mathrm{PM}_{2.5}\right)$ and below $10 \mu \mathrm{m}\left(\mathrm{PM}_{10}\right)$, and ultrafine particles (UFP, $0.01-0.1 \mu \mathrm{m}$ in diameter) were measured at a central measurement site in Augsburg throughout the entire study period as described previously. ${ }^{24} 25$ Sulphate measurements only started on 25 April 2007. Missing ozone, UFP and meteorological values were not replaced as $<1 \%$ of the $1 \mathrm{~h}$ averages were missing (ozone and meteorological variables) or no parallel measurements with other devices were available (UFP and sulphate).

\section{Statistical analysis}

Analyses were performed with SAS (V9.2; SAS Institute). In order to compare the ECG parameters between healthy participants and individuals with T2D or IGT, we used mixed models with a random participant effect including a dummy variable for the subgroup effect. A first order autoregressive covariance structure has been proven to be sufficient to account for the dependencies between the repeated ECG recordings.

The $p$ value of the subgroup effect indicates whether the ECG parameters differ significantly between the groups. The patient characteristics of both groups were compared using a t test for metric variables and a $\chi^{2}$ test for categorical variables. In case of less than five observations in one category, Fisher's exact test was used.

Ozone effects were estimated using additive mixed models with a random participant effect and a first order autoregressive covariance structure. Tcomp was log-transformed in order to produce normally distributed residuals. A confounder selection was conducted for each ECG parameter separately. Model selection was carried out by minimising Akaike's information criterion. Continuous confounders were included linearly or smoothly as P-splines depending on the Akaike's information criterion value. Air temperature and relative humidity with the same lag as the ozone term and long-term time trend were forced into the model. Barometric pressure with the same lag as the analysed ozone lag and day of the week were only included in case of model fit improvement. Two $1 \mathrm{~h}$ intervals of HR were excluded because of large Studentised residuals.

After assessing the confounder model, $1 \mathrm{~h}$ averages of ozone concurrent with the $1 \mathrm{~h}$ averages of ECG measurements and up to $4 \mathrm{~h}$ before the ECG recordings were separately added to the confounder model and the effects were estimated linearly. Furthermore, we checked whether the association between ozone and the ECG parameters differed between healthy participants with a potential genetic predisposition and subjects with IGT or T2D by conducting a stratified analysis.

Gender (male vs female) and age ( $<65$ years vs $\geq 65$ years) were included as potential modifiers of the ozone effects. 
As ozone levels are known to be lower in winter and indoors, we created for each $1 \mathrm{~h}$ ECG interval a variable indicating whether the participant stayed indoors or the ECG recording was performed in winter (October-March) versus the participant was outdoors at least once during the $1 \mathrm{~h}$ recording and the ECG was carried out in summer (April-September). Interaction effects with ozone were calculated using this variable.

In order to check the robustness of the ozone effects, we additionally adjusted our models for sulphate, UFP, $\mathrm{PM}_{10}$ and $\mathrm{PM}_{2.5}$, respectively. We either included the air pollutants with the same lag as the analysed ozone lag or with the most influential lag. As ECG parameters might have a diurnal rhythm, we included time of the day (morning vs afternoon) in the models. We also excluded individuals with coronary artery disease, angina pectoris or an MI, as well as occasional smokers. Additionally, we only included participants without intake of $\beta$-adrenergic receptor blockers ( $\beta$-blockers). As a further sensitivity analysis, ozone effects were estimated smoothly as Psplines in order to check the linearity of the relationship between ozone and ECG parameters.

\section{RESULTS}

\section{Study population and clinical measurements}

Overall, 110 participants (32 individuals with T2D, 32 with IGT, and 46 with a potential genetic susceptibility) with 363 valid ECG recordings (average duration: $5.8 \mathrm{~h}$ ) comprising more than $20001 \mathrm{~h}$ intervals were available for analysis. For nine participants, only one ECG recording consisting of at least five (repeated) $1 \mathrm{~h}$ intervals was available. Table 1 describes the baseline characteristics and the ECG parameters of the nonsmoking participants.

Participants with T2D or IGT were older, more often overweight, less hypertensive and included more individuals with a previous MI in comparison to healthy participants with a potential genetic predisposition. As expected, elevated levels of glycosylated haemoglobin A1c and use of antidiabetic medication was only observed in participants with T2D or IGT. With regard to the ECG parameters, we only detected a significant difference between the two groups for Tamp, with higher values in healthy participants. Spearman correlation coefficients between ECG parameters were calculated for each ECG recording separately. According to the median of these

Table 1 Description of the study population and ECG parameters

\begin{tabular}{|c|c|c|c|c|c|c|c|}
\hline & & $\begin{array}{l}\text { All }(\mathbf{N}=110) \\
\text { Mean (SD) }\end{array}$ & \multicolumn{2}{|c|}{$\begin{array}{l}\text { T2D or IGT }(\mathrm{N}=64) \\
\text { Mean (SD) }\end{array}$} & \multicolumn{2}{|c|}{$\begin{array}{l}\text { Healthy (N=46) } \\
\text { Mean (SD) }\end{array}$} & p Value \\
\hline \multicolumn{2}{|l|}{ Age (years) } & $61.6(11.7)$ & \multicolumn{2}{|c|}{$66.1(8.1)$} & \multicolumn{2}{|c|}{$55.4(13.1)$} & $<0.001^{*}$ \\
\hline \multirow{2}{*}{\multicolumn{2}{|c|}{ BMI $\left(\mathrm{kg} / \mathrm{m}^{2}\right)$}} & $28.6(5.3)$ & \multicolumn{2}{|c|}{$30.1(4.7)$} & \multicolumn{2}{|c|}{$26.5(5.6)$} & $<0.001 *$ \\
\hline & & N (\%) & \multicolumn{2}{|c|}{$\mathbf{N}(\%)$} & \multicolumn{2}{|c|}{ N (\%) } & \\
\hline \multicolumn{8}{|l|}{ Age (years) } \\
\hline$\leq 65$ & & $61(56)$ & \multicolumn{2}{|c|}{$27(42)$} & \multicolumn{2}{|c|}{$34(74)$} & $0.004 \dagger$ \\
\hline$>65$ & & $49(44)$ & \multicolumn{2}{|c|}{$34(58)$} & \multicolumn{2}{|c|}{$12(26)$} & \\
\hline \multicolumn{8}{|l|}{ BMI $\left(\mathrm{kg} / \mathrm{m}^{2}\right)$} \\
\hline$\leq 30$ & & $72(65)$ & \multicolumn{2}{|c|}{$34(53)$} & \multicolumn{2}{|c|}{$38(82)$} & $0.001 \dagger$ \\
\hline$>30$ & & $38(35)$ & \multicolumn{2}{|c|}{$30(47)$} & \multicolumn{2}{|c|}{$8(18)$} & \\
\hline \multicolumn{8}{|l|}{ Gender } \\
\hline Male & & $69(63)$ & \multicolumn{2}{|c|}{$42(66)$} & \multicolumn{2}{|c|}{27 (59) } & $0.46 \dagger$ \\
\hline Female & & $41(37)$ & \multicolumn{2}{|c|}{$22(34)$} & \multicolumn{2}{|c|}{$19(41)$} & \\
\hline \multicolumn{8}{|l|}{ Smoking } \\
\hline Never smoker & & $50(45)$ & \multicolumn{2}{|c|}{$26(41)$} & \multicolumn{2}{|c|}{$24(52)$} & $0.06 \neq$ \\
\hline Ex-smoker & & $55(50)$ & 37 & & 18 & & \\
\hline Occasional smoker & & $5(5)$ & 1 & & 4 & & \\
\hline $\mathrm{HbA1c}$ & & & & & & & \\
\hline$<6.5 \%$ & & $95(86)$ & 49 & & 46 & & $<0.001 \ddagger$ \\
\hline$\geq 6.5 \%$ & & $15(14)$ & 15 & & & & \\
\hline History of & & & & & & & \\
\hline Coronary heart disease & & $7(6)$ & 4 & & 3 & & $1.00 \neq$ \\
\hline Angina pectoris & & $5(8)$ & 5 & & 1 & & $0.40 \neq$ \\
\hline Myocardial infarction & & $6(5)$ & & & & & $0.04 \ddagger$ \\
\hline Hypertension & & $49(45)$ & 23 & & 26 & & $0.03 \dagger$ \\
\hline Medication use & & & & & & & \\
\hline Antidiabetic medication & & $18(28)$ & 18 & & & & $<0.001 \neq$ \\
\hline$\beta$-Adrenergic receptor blo & kers & $28(25)$ & 19 & & & & $0.23 \dagger$ \\
\hline Statins & & $19(17)$ & 13 & & & & $0.32 \dagger$ \\
\hline & $\mathbf{N}$ & Mean (SD) & $\mathbf{N}$ & Mean (SD) & $\mathbf{N}$ & Mean (SD) & \\
\hline ECG parameters & & & & & & & \\
\hline Heart rate (beats/min) & 2081 & $78.4(13.0)$ & 1202 & $79.0(14.3)$ & 879 & $77.6(10.9)$ & $0.56 \S$ \\
\hline T-wave amplitude $(\mu \mathrm{V})$ & 2060 & $330(134)$ & 1185 & 305 (127) & 875 & $364(135)$ & $0.02 \S$ \\
\hline T-wave complexity (\%) & 2083 & $18.0(8.5)$ & 1203 & $17.5(7.5)$ & 880 & $18.7(9.7)$ & $0.43 \S$ \\
\hline OTc-interval (ms) & 2083 & $440.5(24.3)$ & 1203 & $443.5(24.3)$ & 880 & $436.3(23.8)$ & $0.08 \S$ \\
\hline
\end{tabular}


correlation coefficients, HR showed a moderate correlation with Tcomp and OTc $(r=0.6)$. Tcomp was negatively correlated with Tamp $(r=-0.6)$. All other ECG parameters were uncorrelated $(r<|0.5|)$. For all further statistical analyses, Tcomp was log-transformed in order to produce normally distributed residuals.

\section{Ozone, air pollution and meteorological data}

During the study period, the $1 \mathrm{~h}$ average concentrations $\pm S D$ were $45.9 \pm 33.3 \mu \mathrm{g} / \mathrm{m}^{3}$ for ozone, $10.8 \pm 7.9^{\circ} \mathrm{C}$ for temperature, $1.4 \pm 1.6 \mu \mathrm{g} / \mathrm{m}^{3}$ for sulphate and $9518 \pm 6902 \mathrm{n} / \mathrm{cm}^{3}$ for UFP. During the entire study period, $1 \mathrm{~h}$ averages of ozone never exceeded the German information $\left(180 \mu \mathrm{g} / \mathrm{m}^{3}\right)$ and alert threshold $\left(240 \mu \mathrm{g} / \mathrm{m}^{3}\right)$. Online supplementary table 1 provides a more detailed description of the air pollutants and meteorological variables. Figure 1 shows the medians over time together with 5 th and 95th percentiles for ozone, air temperature, sulphate and UFP. Ozone values were higher in summer and showed a strong diurnal pattern with highest values between 2 and 4 pm (14:00 to 16:00 h). Sulphate and UFP levels were higher in winter, with a peak in the morning hours for UFP. Ozone was uncorrelated $(|\mathrm{r}|<0.3)$ with sulphate, $\mathrm{PM}_{10}, \mathrm{PM}_{2.5}$ or UFP during the summer but showed a moderate correlation $(r<-0.6)$ with these air pollutants in winter. The correlation coefficients between ozone and temperature were 0.59 and 0.38 in summer and winter, respectively. $\mathrm{PM}_{10}, \mathrm{PM}_{2.5}$ and sulphates showed a moderate and strong correlation in summer and winter, respectively, whereas UFP was uncorrelated with other air pollutants.

\section{Effects of ozone on ECG parameters}

Figure 2 shows the per cent changes in the mean ECG parameters for each $20 \mu \mathrm{g} / \mathrm{m}^{3}$ ( $\hat{=} 10 \mathrm{ppb}$ ) increase in ozone together

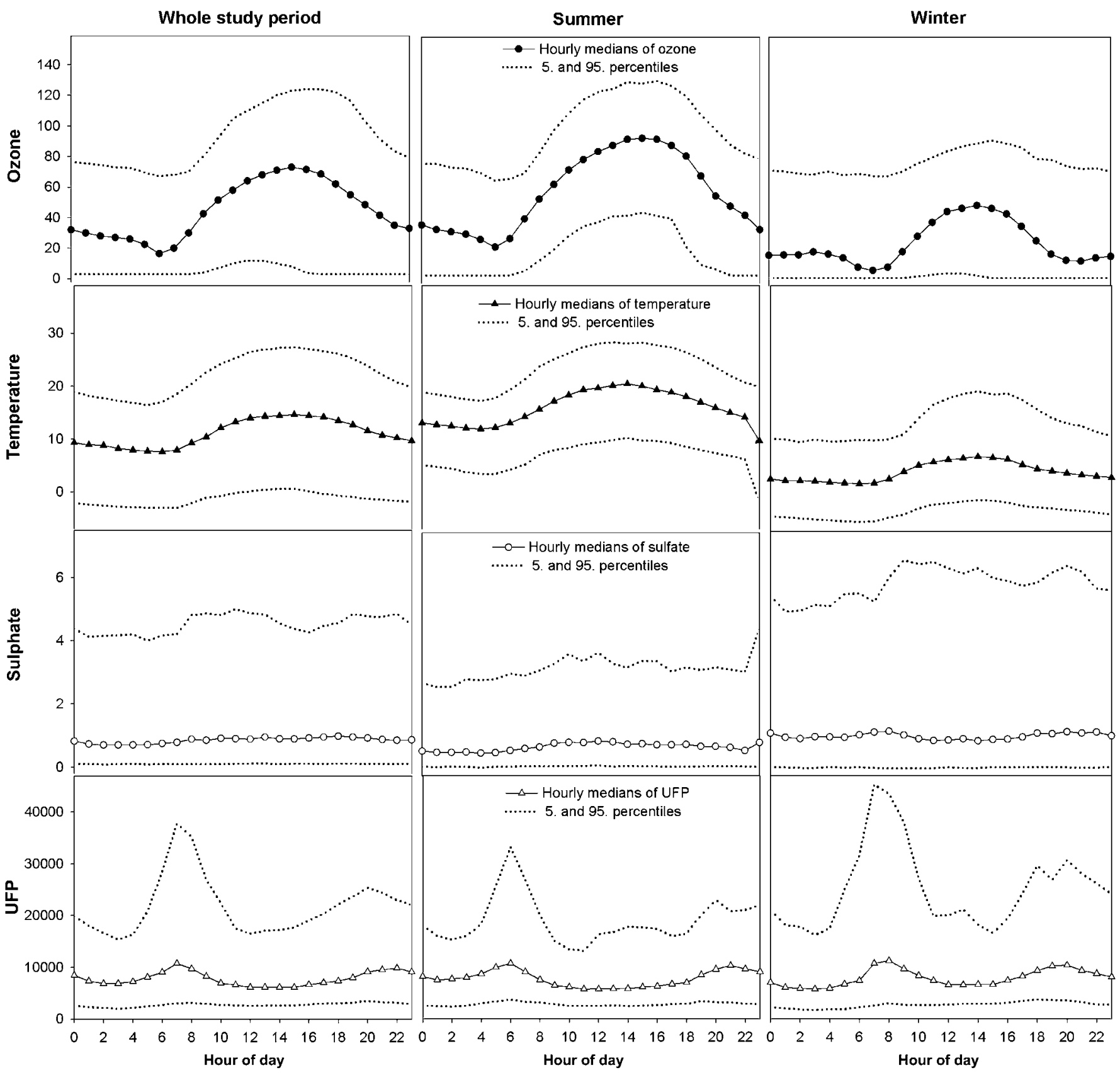

Figure 1 Medians and 5th and 95th percentiles of ozone, air temperature, sulphate and ultrafine particles (UFP) (1 h intervals) at the same time of the day for the whole study period and for summer (April-September) and winter (October-March) separately. 
with $95 \%$ CIs. Elevated ozone levels led to a marginal concurrent $0.54 \%$ (95\% CI $-0.07 \%$ to $1.16 \%)$ increase in HR and to $1-4 \mathrm{~h}$ delayed increases of about $0.6-0.7 \%$ in all participants, showing the strongest association with a $2 \mathrm{~h}$ lag $(0.78 \% ; 0.18 \%$ to $1.37 \%)$. Ozone effects were more pronounced in individuals with T2D or IGT for all lags, showing per cent changes in HR of about $1 \%$. HR did not change due to ozone exposure in healthy individuals with a potential genetic predisposition. We observed concurrent and $1 \mathrm{~h}$ lagged $\mathrm{T}$-wave flattening of $-1.31 \%(-2.19 \%$ to $-0.42 \%)$ and $-1.32 \%(-2.19 \%$ to $-0.45 \%)$ associated with elevated ozone levels, respectively. This association was

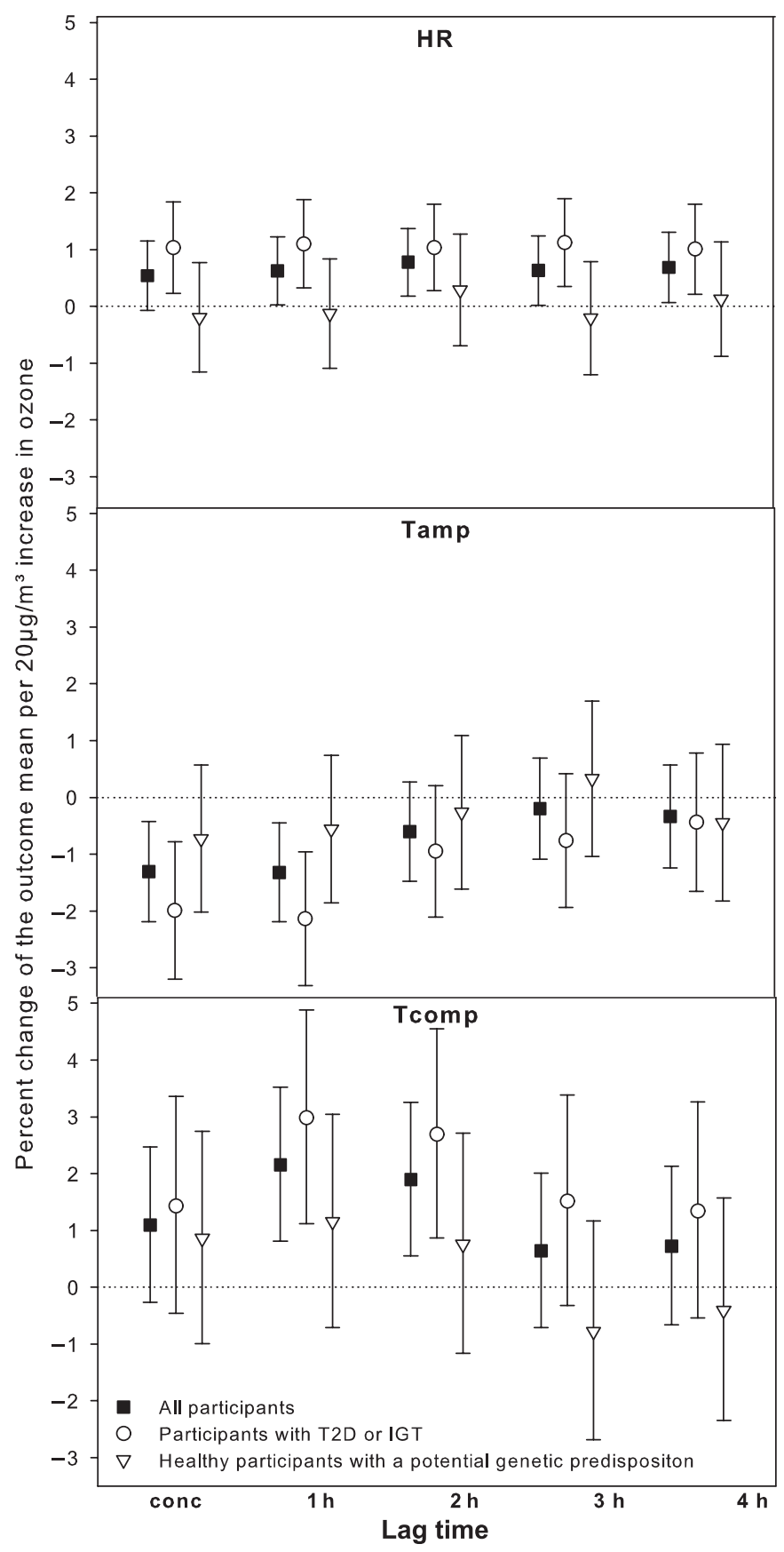

Figure 2 Concurrent (Conc) and 1-4 h delayed effects of $1 \mathrm{~h}$ averages of ozone on $1 \mathrm{~h}$ averages of heart rate (HR), T-wave amplitude (Tamp) and T-wave complexity (Tcomp) in all participants, in individuals with type 2 diabetes (T2D) or impaired glucose tolerance (IGT) and in healthy individuals with a potential genetic predisposition. predominantly detected in participants with T2D or IGT (concurrent and $1 \mathrm{~h}$ lagged ozone effects: $-1.99 \%(-3.20 \%$ to $-0.78 \%)$ and $-2.14 \%(-3.32 \%$ to $-0.96 \%)$ ), whereas healthy subjects showed a weaker reduction in Tamp. Furthermore, Tcomp increased in association with elevated ozone levels among all participants by $2.12 \%(0.81 \%$ to $3.52 \%)$ and $1.89 \%$ $(0.55 \%$ to $3.26 \%)$ with a lag of $1 \mathrm{~h}$ and $2 \mathrm{~h}$, respectively. Again, only participants with metabolic disorders reacted to ozone exposure. Analysing the association between ozone exposure and ECG parameters in participants with T2D and IGT separately led to similar ozone effects compared to the combined analysis of all participants with metabolic disorders. However, CIs slightly widened, probably because of the lower sample size in the subgroups. No ozone effects were seen for QTc in either subgroup. Initially, we were also interested in ozone effects on time and frequency domain parameters as well as in temperature effects on repolarisation parameters. However, we did not observe ozone effects on time and frequency domain parameters. We also did not detect any temperature effects on repolarisation parameters either with or without adjustment for ozone (data not shown).

Some $69 \%$ of all $1 \mathrm{~h}$ ECG intervals were recorded in winter or when the participants were indoors. Hence, $31 \%$ of all $1 \mathrm{~h}$ ECG intervals were recorded in summer or while the participants were outdoors (hourly average duration outdoors: $21 \pm 18 \mathrm{~min}$ ). The ozone effect modifications by this variable are shown in figure 3. We detected the strongest effect modification on HR. We observed concurrent and lagged $0.9-1.1 \%$ increases in HR associated with elevated ozone levels when $1 \mathrm{~h}$ ECG intervals were recorded in summer and outdoors. The strongest effect was observed with a lag of $2 \mathrm{~h}(1.15 \% ; 0.47 \%$ to $1.84 \%)$. HR was not altered by increases in ozone during winter or when indoors. Ozone effects on Tamp and Tcomp were slightly more pronounced when participants were outdoors during summer compared to ECG recordings in winter or indoors. However, the ozone effect modifications were not significant. Furthermore, we detected no interaction effects by age and gender (data not shown).

Since ozone effects on HR were similar for all lags and strongest with a lag of $1 \mathrm{~h}$ for Tamp and Tcomp, the results of the sensitivity analyses based on ECG recordings of all participants are shown only for a lag of $1 \mathrm{~h}$ (table 2 ). We only show ozone effects additionally adjusted for air pollutants with the same lag as the analysed ozone lag, as the inclusion of the most influential lag led to similar ozone effects.

Ozone effects on HR slightly strengthened when the model was adjusted for other air pollutants. The association between ozone and Tamp or Tcomp became stronger when the model was adjusted for sulphate or PM but weakened when UFP was included as a confounder. In general, the additionally included air pollutants showed a weaker association with ECG parameters than ozone (see online supplementary table 2). The inclusion of time of day led to strongly decreased ozone effects for all ECG parameters, probably reflecting the fact that both ECG parameters and ozone itself have diurnal rhythms, leading to competing effects with time of day in the confounder model. We observed similar variability in the ozone effects when the effect modification by the variable indicating the individuals' location and season, was also included (see table 2).

When the ECG recordings of the 28 and 15 participants with an intake of $\beta$-blockers and an underlying coronary disease, respectively, as well as the five occasional smokers were excluded, the association between ozone and ECG parameters did not change. There was no evidence for any deviation from 


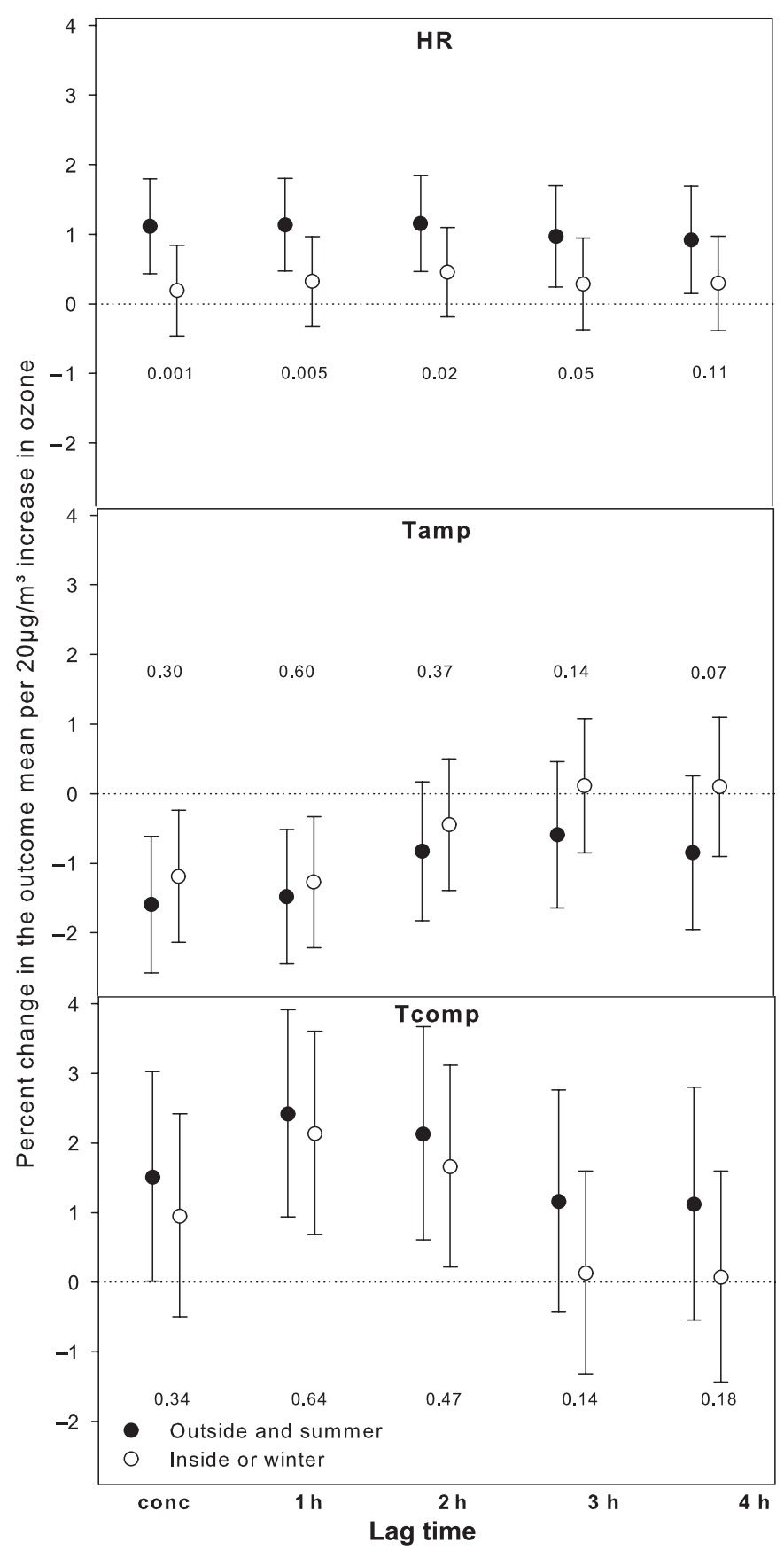

Figure 3 Ozone effects on heart rate (HR), T-wave amplitude (Tamp) and T-wave complexity (Tcomp) modified by a variable indicating 'indoors or winter (October-March)' versus 'outdoors and summer (April-September)'. p Values of interaction are indicated. Conc, concurrent.

linearity of the relationship between ozone and ECG parameters (see online supplementary figure 1).

\section{DISCUSSION}

\section{Summary}

We observed concurrent and 1-4 h lagged increases in $\mathrm{HR}$ in association with elevated ozone levels. These effects were stronger when the participants were outdoors in summer. Furthermore, increases in ozone led to $\mathrm{T}$-wave flattening and an increase in $\mathrm{T}$-wave complexity during the entire study period. In general, ozone effects were only observed in individuals with metabolic disorders. Healthy individuals with a potential genetic predisposition on the detoxification pathway did not show significant changes in $\mathrm{HR}$ and repolarisation due to ozone exposure.

\section{Ozone effects}

Several studies observed an association between elevated ozone concentrations and adverse cardiac events such as MI, ${ }^{12}$ arterial fibrillation ${ }^{18} 26$ and cardiac mortality. ${ }^{6}$ Inhaled ozone exerts oxidative stress by reacting with biomolecules and forming free radicals which trigger local inflammation in the lung. ${ }^{18}$ This possibly leads to systemic inflammation as well as autonomic dysfunction. ${ }^{27} 28$ In accordance with the latter, Zanobetti et al ${ }^{8}$ and Gold et $a l^{29}$ reported an association between increased ambient ozone levels and a reduction in RMSSD in elderly subjects. A study conducted in young and healthy individuals observed negative ozone effects on RMSSD, the SD of normalto-normal intervals, and high and low frequency. Overall, a limited number of studies have investigated the effects of ozone on HRV parameters and there is no epidemiological study on ozone effects on repolarisation. A chamber study ${ }^{21}$ explored the combined and separate effects of concentrated ambient particles (CAP) and ozone on repolarisation parameters (interval from $\mathrm{T}$-wave peak to $\mathrm{T}$-wave end ( $\mathrm{Tp}-\mathrm{e}$ ) and $\mathrm{OT}$ dispersion). The authors detected an increased Tp-e and $\mathrm{QT}$ dispersion in participants who were exposed to both CAP and ozone compared to participants exposed to filtered air. Increases in Tp-e were also observed for ozone exposure only. In our study, we observed increased HR in association with elevated ozone levels indicating activation of the sympathetic nervous system. Correspondingly, many authors reported an elevated HR in association with increases in $\mathrm{PM}_{2.5}{ }^{30-34}$

In addition, we observed rapid T-wave flattening and an increase in Tcomp in association with ozone exposure. Accordingly, Henneberger ${ }^{11}$ et al detected a $-6.5 \%(-10.8 \%$ to $-2.0 \%)$ decrease and a $0.8 \%(0.2 \%$ to $1.5 \%)$ increase in Tamp and Tcomp measured, respectively, in association with an IOR increase in the $6 \mathrm{~h}$ averages of $\mathrm{PM}_{2.5}$ in ischaemic heart disease patients. In comparison to our study, IOR increases in ozone ( $\left.\hat{=} 54 \mu \mathrm{g} / \mathrm{m}^{3}\right)$ led to a weaker decrease in $\operatorname{Tamp}(-3.0 \% ;-5.0 \%$ to $-1.0 \%)$ and a larger increase in Tcomp (5.0\%; 1.9\% to 8.3\%) with a lag of $1 \mathrm{~h}$. Furthermore, Schneider et al ${ }^{10}$ observed $\mathrm{PM}_{2.5}$ effects on Tamp and Tcomp with a delay of $1-2$ days. It is important to note that Henneberger et $a l^{11}$ and Schneider et $a l^{10}$ analysed 5 min intervals of repolarisation parameters recorded while the participants rested, whereas our participants pursued their daily routines. Our findings indicate rapidly developing repolarisation abnormalities in response to increased ozone levels. Such changes might be precursors of cardiac events since it has been shown that $\mathrm{T}$-wave alternans and $\mathrm{T}$-wave abnormalities are reliable predictors for sudden cardiac death ${ }^{35}$ and coronary syndromes. ${ }^{36}$

Various authors reported OT changes in association with increases in traffic-related air pollutants. ${ }^{9-13}$ However, in our study QTc did not show any association with ozone exposure.

We only observed an increased $\mathrm{HR}$ in association with elevated ozone levels when participants were outdoors during the summer. We detected no change in HR in winter or while participants were indoors. Since ozone concentrations are generally negligible indoors and mostly very low in winter, these findings are reasonable. However, ozone effects on Tamp and Tcomp were only very slightly modified by the variable indicating the season and location of the participants. We therefore hypothesise that repolarisation parameters are more responsive 
Table 2 Ozone effects with a lag of $1 \mathrm{~h}$ on ECG parameters based on different confounder models for the whole study period and modified by a variable indicating the individuals' location and the season during the $1 \mathrm{~h}$ ECG recording

\begin{tabular}{|c|c|c|c|c|c|c|c|}
\hline & \multirow[b]{2}{*}{ Confounder } & \multicolumn{2}{|c|}{ Whole study period } & \multicolumn{2}{|l|}{ Inside or winter } & \multicolumn{2}{|c|}{ Outside and summer } \\
\hline & & $\begin{array}{l}\text { \% Of ozone } \\
\text { measurements* }\end{array}$ & $\%$ Change $(95 \%$ Cl) & $\begin{array}{l}\text { \% Of ozone } \\
\text { measurements* }\end{array}$ & $\%$ Change (95\% CI) & $\begin{array}{l}\text { \% Of ozone } \\
\text { measurements* }\end{array}$ & $\%$ Change $(95 \% \mathrm{CI})$ \\
\hline \multirow[t]{4}{*}{ HR } & Main model & 100 & $0.62 \%(0.02 \%$ to $1.22 \%)$ & 100 & $0.32 \%(-0.33 \%$ to $0.97 \%)$ & 100 & $1.13 \%(0.47 \%$ to $1.80 \%)$ \\
\hline & + UFP $†$ & 97 & $0.81 \%(0.15 \%$ to $1.46 \%)$ & 96 & $0.44 \%(-0.27 \%$ to $1.16 \%)$ & 99 & $1.25 \%(0.55 \%$ to $1.95 \%)$ \\
\hline & $+\mathrm{PM}_{2.5} \dagger$ & 100 & $0.82 \%(0.21 \%$ to $1.46 \%)$ & 100 & $0.56 \%(-0.12 \%$ to $1.24 \%)$ & 100 & $1.29 \%(0.61 \%$ to $1.97 \%)$ \\
\hline & $+\mathrm{PM}_{10} \dagger$ & 100 & $0.85 \%(0.22 \%$ to $1.48 \%)$ & 100 & $0.56 \%(-0.13 \%$ to $1.24 \%)$ & 100 & $1.28 \%(0.60 \%$ to $1.96 \%)$ \\
\hline \multirow{5}{*}{ Tamp } & + Sulphate $†$ & 96 & $-1.40 \%(-2.29 \%$ to $-0.51 \%)$ & 96 & $-1.37 \%(-2.35 \%$ to $-0.40 \%)$ & 95 & $-1.52 \%(-2.50 \%$ to $0.53 \%)$ \\
\hline & + UFP† & 97 & $-1.18 \%(-2.13 \%$ to $-0.24 \%)$ & 95 & $-1.06 \%(-2.10 \%$ to $-0.02 \%)$ & 99 & $-1.40 \%(-2.42 \%$ to $0.39 \%)$ \\
\hline & $+\mathrm{PM}_{2.5} \dagger$ & 100 & $-1.50 \%(-2.40 \%$ to $-0.59 \%)$ & 100 & $-1.50 \%(-2.50 \%$ to $-0.50 \%)$ & 100 & $-1.63 \%(-2.61 \%$ to $0.65 \%)$ \\
\hline & $+\mathrm{PM}_{10} \dagger$ & 100 & $-1.54 \%(-2.47 \%$ to $-0.63 \%)$ & 100 & $-1.54 \%(-2.54 \%$ to $-0.54 \%)$ & 100 & $-1.65 \%(-2.64 \%$ to $0.67 \%)$ \\
\hline & + Time of day & 100 & $-0.85 \%(-1.71 \%$ to $0.02 \%)$ & 100 & $-0.89 \%(-1.79 \%$ to $0.08 \%)$ & 100 & $-0.95 \%(-1.91 \%$ to $0.01 \%)$ \\
\hline \multirow[t]{2}{*}{ Tcomp } & Main model & 100 & $2.16 \%(0.81 \%$ to $3.52 \%)$ & 100 & $2.13 \%(0.68 \%$ to $3.60 \%)$ & 100 & $2.42 \%(0.94 \%$ to $3.92 \%)$ \\
\hline & + Time of day & 100 & $1.54 \%(0.21 \%$ to $2.90 \%)$ & 100 & $1.60 \%(0.16 \%$ to $3.06 \%)$ & 100 & $1.77 \%(0.30 \%$ to $3.36 \%)$ \\
\hline
\end{tabular}

Main model: time trend, air temperature and relative humidity; winter: October-March; summer: April-September.

*Observations with missing values in outcome or confounder variables were removed.

†Air pollutants were included with the same lag as the analysed ozone lag.

$\mathrm{HR}$, heart rate; $\mathrm{PM}_{2.5}$, particulate matter with an aerodynamic diameter below $2.5 \mu \mathrm{m} ; \mathrm{PM}_{10}$, particulate matter with an aerodynamic diameter below $10 \mu \mathrm{m}$; Tamp, $\mathrm{T}$-wave amplitude; Tcomp, T-wave complexity; UFP, ultrafine particles.

to any concentration of ozone exposure even when exposure levels are low during winter. Accordingly, we observed in general ozone effects that were two to three times stronger on Tamp and Tcomp than on HR. However, it is of course also possible that the effect modification occurred by chance only.

\section{Susceptible individuals}

The risk of developing coronary artery disease or having an MI is increased in persons with T2D. ${ }^{37}$ It has also been shown that insulin resistance might cause a reduction in the autonomic nervous system leading to reduced HRV in individuals with T2D and in those with IGT. ${ }^{38}$ Furthermore, the authors reported a stronger risk for ischaemic cerebrovascular events ${ }^{2}$ and outof-hospital deaths ${ }^{6}$ in individuals with diabetes compared to individuals without diabetes in association with elevated ozone levels. Therefore, we assumed that participants with T2D or IGT might be especially susceptible to ozone. In agreement with our hypothesis, we observed T-wave flattening and an increased Tcomp and HR in association with ozone exposure in particular for this subgroup.

GSTM1 encodes a phase II enzyme that can scavenge oxygen free radicals and metabolise reactive oxygen species. Since inhaled ozone induces systemic oxidative stress, we initially hypothesised that people with a GSTM1 deletion are unable to handle oxidative stress as well as others and may be more responsive to ozone. However, we observed no ozone effects on ECG parameters in our subgroup of individuals with a potential genetic predisposition. In accordance with our findings, other epidemiological studies also did not detect an air pollution effect modification by GSTM1 on cardiovascular health outcomes. ${ }^{39} 40$ However, Schwartz et al ${ }^{41}$ and Romieu et al ${ }^{42}$ reported a stronger decrease in HRV and an increased occurrence of respiratory symptoms in individuals with a GSTM1 deletion compared to individuals without the deletion in association with increases in $\mathrm{PM}_{2.5}$ and ozone, respectively.
The different responses to ozone exposure of participants with diabetes or IGT and participants with a potential genetic predisposition might be explained not only by the underlying metabolic disorders but also by differences in other patient characteristics. Individuals with diabetes or IGT were older and more often overweight and comprised more ex-smokers and $\mathrm{MI}$ survivors but fewer subjects with hypertension compared to the subgroup of healthy participants with a potential genetic predisposition. A combination of all these factors possibly affected susceptibility to ozone. Furthermore, our study included 64 participants ( $\sim 2001 \mathrm{~h}$ ECG recordings) with metabolic disorders but only 46 subjects ( $~ 8801 \mathrm{~h}$ ECG recordings) with a potential genetic predisposition. It may have been due to the smaller sample size that we did not detect ozone effects in healthy participants with potential genetic predisposition.

Some authors reported stronger ozone effects in the elderly ( $\geq 65$ years). ${ }^{1}{ }^{17}$ It has also been shown that women react more strongly to ozone exposure ${ }^{6} 17$ since they are presumed to have a greater pulmonary responsiveness than men. ${ }^{43}$ However, in our study ozone effects were not modified by gender or age. This is in agreement with a study by Ren et al ${ }^{44}$ who also did not observe ozone effect modifications on mortality by patient characteristics.

\section{Strengths and limitations}

A strength of our study is its ability to analyse intra-individual variation in $1 \mathrm{~h}$ averages of ECG parameters measured repeatedly in up to four ECG recordings with an average duration of $5.8 \mathrm{~h}$ while participants pursued their daily tasks. Models were adjusted for long-term time trends and meteorological variables to account for the possibility that the detected associations resulted from meteorological influences or seasonal differences alone. We controlled for circadian variation by design as the repeated ECG recordings started at the same time $( \pm 2 h)$ for 
each participant. Furthermore, as a sensitivity analyses, we also included time of day (morning vs afternoon) as a possible confounder. This led to substantially decreased ozone effects. However, as ozone levels increase during the day, time of day might act as a surrogate of ozone. This possibly led to the problem of multicollinearity and weakened the ozone effects. A further strength of our study are the conducted two-pollutant models. Ozone effects might be confounded by other secondary or combustion-related air pollutants produced concurrently with ozone. Franklin and Schwartz ${ }^{20}$ observed substantially decreased ozone effects on mortality when adjusting for sulphate. However, in a study by Gryparis et $\mathrm{al}^{4}{ }^{4}$ ozone effects on mortality remained statistically significant and of comparable magnitude in two-pollutant models additionally including sulphur dioxide or $\mathrm{PM}_{10}$. It is important to point out that in Europe sulphate and ozone have different seasonal patterns than in North America where both sulphate and ozone peak in summer. Since our analyses showed only small changes in ozone effects when adjusting for UFP or sulphate, we assume that our observed ozone effects were not confounded by UFP or sulphate.

A limitation of our study is that outdoor ozone exposure was only obtained from central site measurements and no personal measurements were available. Exposure misclassification might have occurred since the participants spent most of their time indoors.

It has been shown that ozone concentrations are lower in airconditioned households. ${ }^{45}$ Since there are only a few indoor sources of ozone and, to our knowledge, our participants did not use air conditioning in their houses, we assume that exposure misclassification due to the use of central site ozone measurements would probably be non-differential and bias the results toward the null.

A further strength of this study is the investigation of ozone effects in particularly susceptible subgroups. On the other hand, the results cannot then be generalised to the whole population.

\section{CONCLUSION}

We observed very short-term increases in HR, T-wave flattening and $\mathrm{T}$-wave complexity in association with increments in ozone. These associations were stronger in individuals with diabetes or prediabetes. Changes in repolarisation might contribute to the underlying pathophysiological changes associated with the link between elevated ozone levels and reported adverse cardiovascular outcomes.

Acknowledgements We thank Dr Wolfgang Rathmann, DDZ, for performing the glucose tolerance tests and providing us with the $\mathrm{HbA} 1 \mathrm{c}$ measurements. We thank PD Dr Meisinger for coordination of the study centre in Augsburg, Germany.

Funding This research has been funded wholly or in part by the United States Environmental Protection Agency through STAR ('Science to Achieve Results') grant RD 832415 to the University of Rochester. It has not been subjected to the Agency's required peer and policy review and therefore does not necessarily reflect the views of the Agency and no official endorsement should be inferred. This study was also supported in part by a grant from the German Federal Ministry of Education and Research (BMBF) to the German Center for Diabetes Research (DZD e.V.). The KORA research platform (KORA, Cooperative Health Research in the Region of Augsburg) and the MONICA Augsburg studies were initiated and financed by the Helmholtz Zentrum München, German Research Center for Environmental Health (formerly GSF, National Research Center for Environment and Health), which is funded by the German Federal Ministry of Education and Research and by the State of Bavaria.

\section{Competing interests None.}

Ethics approval This study was conducted with the approval of Ethics Commission of the Bavarian Chamber of Physicians ('Bayerische Landesaerztekammer').

Contributors $\mathrm{RH}$ performed the statistical analyses, interpreted the results and drafted the manuscript. SB interpreted the results, coordinated the data management and revised the drafted manuscript. WZ analysed the ECG parameters and critically read the manuscript. UK was involved in the study planning and critically read the manuscript. MP determined the exposure variables and critical read of the manuscript. UG performed the data management and critically read the manuscript. PB was involved in the planning and implementation of the study and critically read the manuscript. AP planned the study, provided the data, interpreted the results and revised the drafted manuscript. AS was involved in the study planning, interpreted the results and revised the drafted manuscript.

Provenance and peer review Not commissioned; externally peer reviewed.

\section{REFERENCES}

1. Ruidavets JB, Cournot M, Cassadou S, et al. Ozone air pollution is associated with acute myocardial infarction. Circulation 2005;111:563-9.

2. Henrotin JB, Zeller M, Lorgis L, et al. Evidence of the role of short-term exposure to ozone on ischaemic cerebral and cardiac events: the Dijon Vascular Project (DIVA) Heart 2010;96:1990-6.

3. Medina-Ramon M, Zanobetti A, Schwartz J. The effect of ozone and PM10 on hospital admissions for pneumonia and chronic obstructive pulmonary disease: A national multicity study. Am J Epidemiol 2006;163:579-88.

4. Gryparis A, Forsberg B, Katsouyanni K, et al. Acute effects of ozone on mortality from the "Air pollution and health: A European approach" project. Am J Respir Crit Care Med 2004;170:1080-7.

5. Bell ML, Dominici F, Samet JM. A meta-analysis of time-series studies of ozone and mortality with comparison to the national morbidity, mortality, and air pollution study. Epidemiology 2005;16:436-45.

6. Stafoggia M, Forastiere F, Faustini A, et al. Susceptibility factors to ozone-related mortality a population-based case-crossover analysis. Am J Respir Crit Care Med 2010;182:376-84.

7. Chuang KJ, Chan CC, Su TC, et al. The effect of urban air pollution on inflammation, oxidative stress, coagulation, and autonomic dysfunction in young adults. $\mathrm{Am} \mathrm{J}$ Respir Crit Care Med 2007;176:370-6.

8. Zanobetti A, Gold DR, Stone PH, et al. Reduction in heart rate variability with traffic and air pollution in patients with coronary artery disease. Environ Health Perspect 2010;118:324-30.

9. Hampel R, Schneider A, Bruske I, et al. Altered Cardiac Repolarization in Association with Air Pollution and Air Temperature among Myocardial Infarction Survivors. Environ Health Perspect 2010;118:1755-61.

10. Schneider A, Neas LM, Graff DW, et al. Association of cardiac and vascular changes with ambient PM2.5 in diabetic individuals. Part Fibre Toxicol 2010;7:14.

11. Henneberger A, Zareba W, Ibald-Mulli A, et al. Repolarization changes induced by air pollution in ischemic heart disease patients. Environ Health Perspect 2005; 113:440-6

12. Liao D, Shaffer ML, Rodriguez-Colon S, et al. Acute adverse effects of fine particulate air pollution on ventricular repolarization. Environ Health Perspect 2010;118:1010-15

13. Baja ES, Schwartz JD, Wellenius GA, et al. Traffic-related air pollution and OT interval: modification by diabetes, obesity, and oxidative stress gene polymorphisms in the normative aging study. Environ Health Perspect 2010;118:840-6.

14. Zanobetti A, Stone PH, Speizer FE, et al. T-wave alternans, air pollution and traffic in high-risk subjects. Am J Cardiol 2009;104:665-70.

15. Roden DM. Keep the OT interval: it is a reliable predictor of ventricular arrhythmias Heart Rhythm 2008;5:1213-15.

16. Greenland P, Xie X, Liu K, et al. Impact of minor electrocardiographic ST-segment and/or T-wave abnormalities on cardiovascular mortality during long-term follow-up. Am J Cardiol 2003;91:1068-74.

17. Medina-Ramon $\mathbf{M}$, Schwartz $\mathrm{J}$. Who is more vulnerable to die from ozone air pollution? Epidemiology 2008;19:672-9.

18. Srebot V, Gianicolo EA, Rainaldi G, et al. Ozone and cardiovascular injury. Cardiovasc Ultrasound 2009;7:30.

19. Hayes JD, Strange RC. Glutathione S-transferase polymorphisms and their biologica consequences. Pharmacology 2000;61:154-66.

20. Franklin M, Schwartz J. The impact of secondary particles on the association between ambient ozone and mortality. Environ Health Perspect 2008;116:453-8.

21. Sivagangabalan G, Spears D, Masse $S$, et al. The effect of air pollution on spatia dispersion of myocardial repolarization in healthy human volunteers. J Am Coll Cardiol 2011;57:198-206.

22. Wichmann HE, Gieger C, Illig T. KORA-gen-resource for population genetics, controls and a broad spectrum of disease phenotypes. Gesundheitswesen 2005;67 (Suppl 1):S26-30.

23. Holle R, Happich $M$, Lowel $H$, et al. KORA-a research platform for population based health research. Gesundheitswesen 2005;67(Suppl 1):S19-25.

24. Cyrys J, Pitz M, Heinrich J, et al. Spatial and temporal variation of particle number concentration in Augsburg, Germany Sci Total Environ 2008;401:168-75.

25. Pitz M, Schmid 0, Heinrich J, et al. Seasonal and diurnal variation of PM2.5 apparent particle density in urban air in Augsburg, Germany Environ Sci Technol 2008;42:5087-93.

26. Rich DQ, Mittleman MA, Link MS, et al. Increased risk of paroxysmal atrial fibrillation episodes associated with acute increases in ambient air pollution. Environ Health Perspect 2006;114:120-3. 
27. Luttmann-Gibson H, Suh HH, Coull BA, et al. Systemic inflammation, heart rate variability and air pollution in a cohort of senior adults. Occup Environ Med 2010;67:625-30.

28. Brook RD, Rajagopalan S, Pope CA III, et al. Particulate Matter Air Pollution and Cardiovascular Disease. An Update to the Scientific Statement From the American Heart Association. Circulation 2010:121:2331-78.

29. Gold DR, Litonjua A, Schwartz J, et al. Ambient pollution and heart rate variability. Circulation 2000;101:1267-73.

30. Chen JC, Cavallari JM Stone PH, et al. Obesity is a modifier of autonomic cardiac responses to fine metal particulates. Environ Health Perspect 2007;115:1002-6.

31. Adar SD, Gold DR, Coull BA, et al. Focused exposures to airborne traffic particles and heart rate variability in the elderly. Epidemiology 2007;18:95-103.

32. Luttmann-Gibson $\mathbf{H}$, Suh $\mathrm{HH}$, Coull BA, et al. Short-term effects of air pollution on heart rate variability in senior adults in Steubenville, Ohio. J Occup Environ Med 2006;48:780-8

33. Peters $\mathbf{A}$, Perz $\mathbf{S}$, Doring $A$, et al. Increases in heart rate during an air pollution episode. Am J Epidemiol 1999;150:1094-8.

34. Pope CAI, Verrier RL, Lovett EG, et al. Heart rate variability associated with particulate air pollution. Am Heart $J$ 1999;138:890-9.

35. Stein PK, Sanghavi D, Sotoodehnia N, et al. Association of Holter-based measures including T-wave alternans with risk of sudden cardiac death in the communitydwelling elderly: the Cardiovascular Health Study. J Electrocardiol 2010;43:251-9.

36. Lin KB, Shofer FS, McCusker C, et al. Predictive value of T-wave abnormalities at the time of emergency department presentation in patients with potential acute coronary syndromes. Acad Emerg Med 2008;15:537-43.
37. Beckman JA, Creager MA, Libby P. Diabetes and atherosclerosis: epidemiology, pathophysiology, and management. JAMA 2002;287:2570-81.

38. Perciaccante A, Fiorentini A, Paris A, et al. Circadian rhythm of the autonomic nervous system in insulin resistant subjects with normoglycemia, impaired fasting glycemia, impaired glucose tolerance, type 2 diabetes mellitus. BMC Cardiovasc Disord 2006:6:19.

39. Chahine T, Baccarelli A, Litonjua A, et al. Particulate air pollution, oxidative stress genes, and heart rate variability in an elderly cohort. Environ Health Perspect 2007:115:1617-22

40. Mordukhovich I, Wilker E, Suh H, et al. Black carbon exposure, oxidative stress genes, and blood pressure in a repeated-measures study. Environ Health Perspect 2009:117:1767-72

41. Schwartz J, Park SK, O’Neill MS, et al. Glutathione-S-transferase M1, obesity, statins, and autonomic effects of particles: gene-by-drug-by-environment interaction. Am J Respir Crit Care Med 2005;172:1529-33.

42. Romieu I, Ramirez-Aguilar M, Sienra-Monge JJ, et al. GSTM1 and GSTP1 and respiratory health in asthmatic children exposed to ozone. Eur Respir $J$ 2006;28:953-9.

43. Reisenauer CS, Koenig J0, McManus MS, et al. Pulmonary response to ozone exposures in healthy individuals aged 55 years or greater. JAPCA 1988;38:51-5.

44. Ren C, Melly S, Schwartz J. Modifiers of short-term effects of ozone on mortality in eastern Massachusetts-a case-crossover analysis at individual level. Environ Health 2010:9:3.

45. Lee K, Parkhurst WJ, Xue JP, et al. Outdoor/indoor/personal ozone exposures of children in Nashville, Tennessee. Air Waste Manag Assoc 2004;54:352-9.

Advancing Postgraduates. Enhancing Healthcare.

The Postgraduate Medical Journal is dedicated to advancing the understanding of postgraduate medical education and training

- Acquire the necessary skills to deliver the highest possible standards of patient care

- Develop suitable training programmes for your trainees

- Maintain high standards after training ends

Published on behalf of the fellowship for Postgraduate Medicine

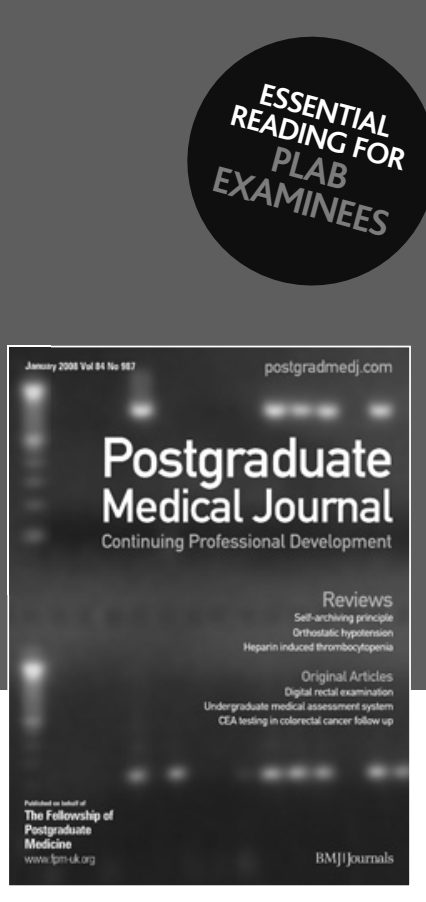

FOR MORE DETAILS OR TO SUBSCRIBE,

VISIT THE WEBSITE TODAY

postgradmedj.com

BMJIJournals 


\section{Immediate ozone effects on heart rate and repolarisation parameters in potentially susceptible individuals}

Regina Hampel, Susanne Breitner, Wojciech Zareba, Ute Kraus, Mike Pitz, Uta Geruschkat, Petra Belcredi, Annette Peters, Alexandra Schneider and for the Cooperative Health Research in the Region of Augsburg (KORA) Study Group

Occup Environ Med 2012 69: 428-436 originally published online November 17, 2011

doi: 10.1136/oemed-2011-100179

Updated information and services can be found at:

http://oem.bmj.com/content/69/6/428

Supplementary
Material

References

Email alerting service
Supplementary material can be found at: http://oem.bmj.com/content/suppl/2011/11/16/oemed-2011-100179.D C1.html

These include:

This article cites 45 articles, 8 of which you can access for free at: http://oem.bmj.com/content/69/6/428\#BIBL

Receive free email alerts when new articles cite this article. Sign up in the box at the top right corner of the online article.

ErrataAn erratum has been published regarding this article. Please see next page or:

http://oem.bmj.com/content/69/8/607.full.pdf

\section{Notes}

To request permissions go to:

http://group.bmj.com/group/rights-licensing/permissions

To order reprints go to:

http://journals.bmj.com/cgi/reprintform

To subscribe to BMJ go to:

http://group.bmj.com/subscribe/ 
2. Bessudnov A, McKee M, Stuckler D. Inequalities in male mortality by occupational class, perceived status and education in Russia, 1994-2006. Eur J Public Health 2012;22:332-7.

3. Nabi H, Kivimaki M, Marmot MG, et al. Does personality explain social inequalities in mortality? The French GAZEL cohort study. Int J Epidemiol 2008:37:591-602.

4. Elovainio M, Ferrie JE, Singh-Manoux A, et al. Socioeconomic differences in cardiometabolic factors: social causation or health-related selection? Evidence from the Whitehall II cohort study, 1991-2004. Am J Epidemiol 2011; 174:779-89.

5. Agardh E, Allebeck P, Hallqvist J, et al. Type 2 diabetes incidence and socio-economic position: a systematic review and meta-analysis. Int J Epidemiol 2011;40:804-18.

\section{Risk estimate of ischaemic heart disease in workers exposed to beryllium}

Mary Schubauer-Berigan and coworkers ${ }^{1}$ presented quantitative beryllium exposure measurements and an increased risk of cor pulmonale (standardised mortality ratio (SMR) 1.17; 95\% CI 1.08 to 1.26 ) in a wellconducted cohort study. However, no risk estimate of ischaemic heart disease (IHD) was reported.

In the mid-1990s, a general hypothesis was launched linking inhalation of particles to the occurrence of IHD in urban as well as working environments by an inflammatory pathway associated with increased blood coagulation. In 2010, the American Heart Association concluded strong epidemiological evidence of a relation between shortterm (days) or long-term exposure (months to years) to $\mathrm{PM}_{2.5}$ (fine particulate matter) urban air pollutants and the occurrence of IHD. Today, studies indicate strong overall mechanistic evidence for a systemic inflammatory response as an intermediary pathway between inhalation of particles and IHD. ${ }^{2}$

Chronic beryllium exposure may stimulate the acquired immune response to release mediators of chronic inflammation in the lung involving cellular and molecular components of innate immunity, and it is this vicious cycle driven by beryllium that results in progressive impairment of lung function, granuloma formation and progression to lung fibrosis. ${ }^{3}$ An association has been suggested between exposure to other agents known to cause pulmonary fibrosis such as silica ${ }^{4}$ and asbestos ${ }^{5}$ and an increased incidence of IHD. Furthermore, one previous US cohort study of beryllium workers observed an increased risk of IHD. ${ }^{6}$

With quantitative exposure estimates being available in the latest cohort of US beryllium workers, Schubauer-Berigan and coworkers have an excellent opportunity to study potential dose-response relations between beryllium exposure and IHD.

\section{Bengt Sjögren}

Correspondence to Dr Bengt Sjögren, Work Environment Toxicology, Institute of Environmental Medicine, Karolinska Institutet, Box 210, Stockholm SE-171 77, Sweden; bengt.sjogren@ki.se

Contributors BS is the sole contributor to this letter.

Provenance and peer review Not commissioned; internally peer reviewed.

Accepted 26 January 2012

Published Online First 1 March 2012

Occup Environ Med 2012;69:607.

doi:10.1136/oemed-2012-100649

\section{REFERENCES}

1. Schubauer-Berigan MK, Couch JR, Petersen MR, et al. Cohort mortality study of workers at seven beryllium processing plants: update and associations with cumulative and maximum exposure. Оссир Environ Med 2011;68:345-53.

2. Brook RD, Rajagopalan S, Pope CA 3rd, et al; American Heart Association Council on Epidemiology and Prevention, Council on the Kidney in Cardiovascular Disease, and Council on Nutrition, Physical Activity and Metabolism. Particulate matter air pollution and cardiovascular disease: an update to the scientific statement from the American Heart Association. Circulation 2010;121:2331-78

3. Sawyer RT, Maier LA. Chronic beryllium disease: an update model interaction between innate and acquired immunity. Biometals 2011;24:1-17.

4. Brown LM, Gridley G, Olsen JH, et al. Cancer risk and mortality patterns among silicotic men in Sweden and Denmark. J Occup Environ Med 1997;39:633-8.

5. Sjögren B. Mortality among British asbestos workers. Letter to the editor. Occup Environ Med 2009;66:854-5.
6. Ward E, Okun A, Ruder A, et al. A mortality study of workers at seven beryllium processing plants. Am J Ind Med 1992;22:885-904.

\section{CORRECTIONS}

doi:10.1136/oemed-2011-100200corr1

P Mikkonen, Eira Viikari-Juntura, Jouko Remes et al. Physical workload and risk of low back pain in adolescence. Occup Environ Med 2012;69:4 284-290. The authors noticed errors concerning the rates of incidence and persistence of LBP on page 3 . Some of the numbers in this section are incorrect. The following sentences are incorrect: In adolescents without LBP at baseline, the incidence of "Reporting LBP" was 29\% in girls and 19\% in boys and that of "Consultation for LBP" was $2 \%$ in both genders. The persistence of "Reporting LBP" was 53\% in girls and $46 \%$ in boys and that of "Consultation for LBP" 19\% in girls and $17 \%$ in boys. The correct version of these sentences is as follows: In adolescents without LBP at baseline, the incidence of "Reporting LBP" was $46 \%$ in girls and 31\% in boys and that of "Consultation for LBP" was $5 \%$ in girls and $4 \%$ in boys. The persistence of "Reporting LBP" was 69\% in girls and $62 \%$ in boys and that of "Consultation for LBP" $23 \%$ in girls and $21 \%$ in boys.

doi:10.1136/oemed-2011-100179corr1

R Hampel, S Breitner, W Zareba et al. Immediate ozone effects on heart rate and repolarisation parameters in potentially susceptible individuals. Occup Environ Med 2012;69:6 428-436. The authors of this paper noticed some errors in the numbers of the Tamp section of table 2 . In the $[95 \%-\mathrm{CI}]$ column for Outside and summer, the first 5 numbers were missing a minus sign. Please see the correct version of the table below. 


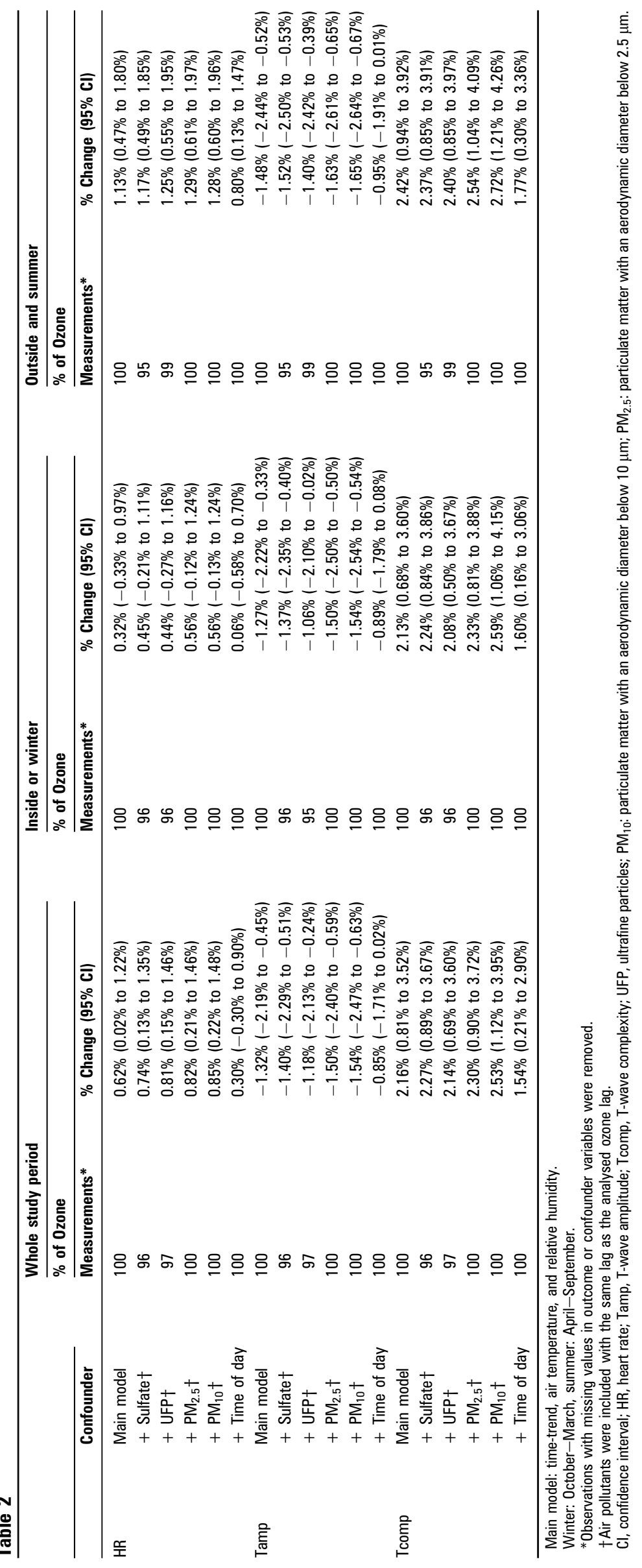

